\title{
Treatment of non-arthritic pseudoparetic shoulders with irreparable massive rotator cuff tears: arthroscopic procedures yield comparable midterm results to reverse arthroplasty
}

Fabian Plachel ${ }^{1,2}$, Paul Siegert ${ }^{1}$, Philipp Moroder ${ }^{1}$, Leo Pauzenberger ${ }^{3}$, Brenda Laky ${ }^{3,4}$, Werner Anderl ${ }^{3,4}$ and Philipp Heuberer ${ }^{3,4^{*}}$

\begin{abstract}
Background: Irreparable massive rotator cuff tears (IMRCTs) are a well-known cause for functional limitation and difficult to treat. Although several joint-preserving as well as joint-replacing procedures were found to provide pain relief and gain of function, midterm results are scarce, particularly in pseudoparetic shoulder joints unaccompanied by severe osteoarthritis. The purpose of this study was to compare the midterm functional outcomes of arthroscopic procedures to those of reverse total shoulder arthroplasty (RTSA) in pseudoparetic shoulders with IMRC Ts unaccompanied by severe osteoarthritis.

Methods: All patients who underwent either joint-preserving (group A) or joint-replacing (group B) procedures for IMRCT unaccompanied by severe osteoarthritis with a pseudoparetic shoulder function were retrospectively included. Clinical assessment included the Constant Score (CS), the Subjective Shoulder Value (SSV) and the Visual Analog Score (VAS) at baseline and at latest follow-up. Furthermore, the complication and revision rates were assessed.

Results: Overall, a total 56 patients were included of whom each 28 patients formed group A (male, 36\%) and B (male, 53\%) with a mean patient age at time of surgery of $70 \pm 7$ years and $72 \pm 7$ years, respectively. The mean follow-up period was $56 \pm 17$ months. At final follow-up, the total CS (group A: $66 \pm 14$ points; group B $54 \pm 15$ points) was significantly increased after arthroscopic treatment when compared to RTSA $(p=0.011)$. However, no significant differences were detected with SSV $(p=0.583)$ and VAS $(p=0.536)$. Although complication rate $(11 \%$ versus $18 \%$ ) was not significantly different ( $p=0.705$ ), number of revision surgeries was significantly higher in group $B$ when compared to group A ( $p=0.041)$.

(Continued on next page)
\end{abstract}

\footnotetext{
* Correspondence: philipp@heuberer.at

${ }^{3}$ Department of Orthopedics, St. Vincent Hospital Vienna, Hartmanngasse 15/

9, 1050 Vienna, Austria

${ }^{4}$ Austrian Research Group for Regenerative and Orthopedic Medicine,

Hartmanngasse 15/9, 1050 Vienna, Austria

Full list of author information is available at the end of the article
}

C The Author(s). 2021 Open Access This article is licensed under a Creative Commons Attribution 4.0 International License, which permits use, sharing, adaptation, distribution and reproduction in any medium or format, as long as you give appropriate credit to the original author(s) and the source, provide a link to the Creative Commons licence, and indicate if changes were made. The images or other third party material in this article are included in the article's Creative Commons licence, unless indicated otherwise in a credit line to the material. If material is not included in the article's Creative Commons licence and your intended use is not permitted by statutory regulation or exceeds the permitted use, you will need to obtain permission directly from the copyright holder. To view a copy of this licence, visit http://creativecommons.org/licenses/by/4.0/. The Creative Commons Public Domain Dedication waiver (http://creativecommons.org/publicdomain/zero/1.0/) applies to the data made available in this article, unless otherwise stated in a credit line to the data. 
(Continued from previous page)

Conclusions: In non-arthritic pseudoparetic shoulders, both joint-preserving and joint-replacing procedures yielded good clinical midterm outcomes for the treatment of degenerative IMRCTs. Despite of comparable functional and satisfactory functional improvement, increased complication rates and surgical invasiveness outweigh the benefits of primary RTSA and therefore reserve this procedure to a second-line treatment in pseudoparetic patients without any signs of severe cuff arthropathy.

Keywords: Irreparable massive rotator cuff tear, Pseudoparesis, Reverse total shoulder arthroplasty, Arthroscopic treatment, Midterm results

\section{Introduction}

The term massive rotator cuff tear (RCT) refers to a demanding shoulder disorder defined by a complete detachment of at least two tendons of the rotator cuff [1]. Over time, massive RCTs lead to chronic rotator cuff degeneration with accompanied myotendinous retraction, muscle atrophy, and fatty infiltration [2-5]. Furthermore, additive disruption of the superior capsule causes cranial migration of the humeral head with consecutive osteoarthritis $[4,6]$. Patients with massive RCTs generally present with complaints of pain and weakness [7, 8]. Larger tears increase the likelihood of functional loss or even pseudoparesis [9], which is defined as an active shoulder elevation of less than $90^{\circ}$ despite of a free passive range of motion [10].

Attempts of anatomical reconstruction often result in pain relief and improved function, but the ability to achieve watertight repair is poor and reported failure rates are higher than $50 \%$ [11]. Determining what constitutes an irreparable massive RCT (IMRCT) is difficult, as multiple factors must be considered, including tearspecific characteristics along with patient-related factors and surgeon's ability. Indeed, appropriate management of patients with IMRCTs without glenohumeral osteoarthritis remains a challenge. A number of palliative treatment options are available, from non-operative to simple debridement with or without biceps tenotomy, open as well as arthroscopic partial repair, patch augmentation, superior capsule reconstruction, tendon transfer, and reversed total shoulder arthroplasty (RTSA) [10, 12-15]. Given the potential of unfavorable results with arthroscopic debridement [16], it is widely accepted to partially repair the rotator cuff most feasibly to convert an unbalanced tear to a functional RCT by obtaining a balanced force-couple [17]. Besides that, RTSA provides a promising option for elderly patients with massive RCTs that may otherwise be considered irreparable or at significant risk of failure, particularly those with less than $90^{\circ}$ of abduction $[18,19]$.

As current literature lacks in comparing different options to treat IMRCTs without advanced osteoarthritis, the optimal treatment for patients suffering concomitant pseudoparesis is yet unknown. The purpose of this retrospective study was to determinate the midterm functional results in patients with pseudoparetic shoulders caused by IMRCT following arthroscopic jointpreserving procedures (including debridement and partial repair) and RTSA. We hypothesized that there is no significant difference in midterm results after arthroscopic treatment and RTSA.

\section{Materials and Methods}

For the purpose of this retrospective study, all consecutive patients who underwent either arthroscopic jointpreserving or open joint-replacing procedures for the treatment of IMRCTs between 2006 and 2009 were assessed for eligibility.

Of whom, we included all patients treated with arthroscopic debridement or partial repair (group A) and those who received RTSA (Anatomical Shoulder Inverse/Reverse System, Zimmer, Warsaw, USA) (group B). Further inclusion criteria for both treatment options were: (I) IMRCT involving at least three tendons with fatty infiltration of the supraspinatus (SSP) or infraspinatus (ISP) muscles greater than stage 2 according to Goutallier et al. [5] or Fuchs et al. [20], detected by preoperative CT or MRI slice-imaging, respectively; (II) absence of discernible osteoarthritis on preoperative radiographs defined as stage 1 to 3 using the Hamada classification system (stage 1 defined as an Acromiohumeral Interval $(\mathrm{AHI}) \geq 6 \mathrm{~mm}$, stage 2 with $\mathrm{AHI} \leq 5 \mathrm{~mm}$, stage 3 with $\mathrm{AHI} \leq 5 \mathrm{~mm}$ and acetabularization of coracoacromial arch, stage 4 with additional glenohumeral narrowing without acetabularization (4a) and with acetabularization (4b), stage 5 with additional humeral head necrosis [21]); (III) pseudoparetic shoulder function (active elevation < $90^{\circ}$ in the presence of free passive range of motion) evaluated clinically as formerly described by Tokish and colleagues [9]; (IV) failed conservative treatment for at least 6 months with persistent debilitating shoulder pain and severely impaired function; and (V) minimum follow-up of 36 months.

We excluded all patients older than 85 years at time of surgery, those in whom a complete non-anatomical (i.e. medialized) arthroscopic repair of the tendons was successfully performed, those with previous fractures or 
tendon tears other than the rotator cuff and the long head of the biceps (LHB) tendon around the affected shoulder joint and those with an incomplete follow-up. The flow chart given in Fig. 1 illustrates the patient selection.

Prior to surgery, each patient received preoperative $\mathrm{x}$ ray examination in three standard planes and slice imaging including either computed tomography or magnetic resonance imaging. For the purpose of this study and to minimize observation bias, two independent investigators retrospectively performed all radiographic gradings, working in consensus. First, plain radiographic imaging were assessed for cuff arthropathy of the affected shoulder and graded using the Hamada classification [21]. Further, tendon involvement was assessed by slice imaging preoperatively and was confirmed intraoperatively. The global fatty degeneration index (GFDI) was calculated as previously described by Goutallier and colleagues [22].

In general, indication for surgery was made individually in accordance with the patient's preference and performed after providing informed consent. All procedures were performed at a single institution by three experienced shoulder surgeons. In group A, arthroscopic treatment was performed in a standard fashion [11]. The patient was placed in a lateral decubitus position with the affected arm prepared and draped. After diagnostic arthroscopy, the rotator cuff was carefully debrided and mobilized to assess reparability. If the horizontal force-couple was considered reparable, vertical mattress sutures using a double-loaded suture anchor were accomplished for the ISP and the subscapularis (SSC) tendon. Beyond that, subacromial soft tissue decompression, while preserving the coracoacromial ligament, was performed in $90 \%$ of the cases together with a tenotomy of the LHB tendon in $57 \%$. The LHB tendon was already missing in $36 \%$ of the patients. The surgical technique for implantation of the RTSA was performed in modification to the method previously described by Werner et al. in 2005 [10]. Duration times of the surgical procedures were recorded. Patients were prospectively followed through their standard of care patient appointments and all midterm data were then retrospectively reviewed in 2019 for study purpose. The institutional review board approved this retrospective study.

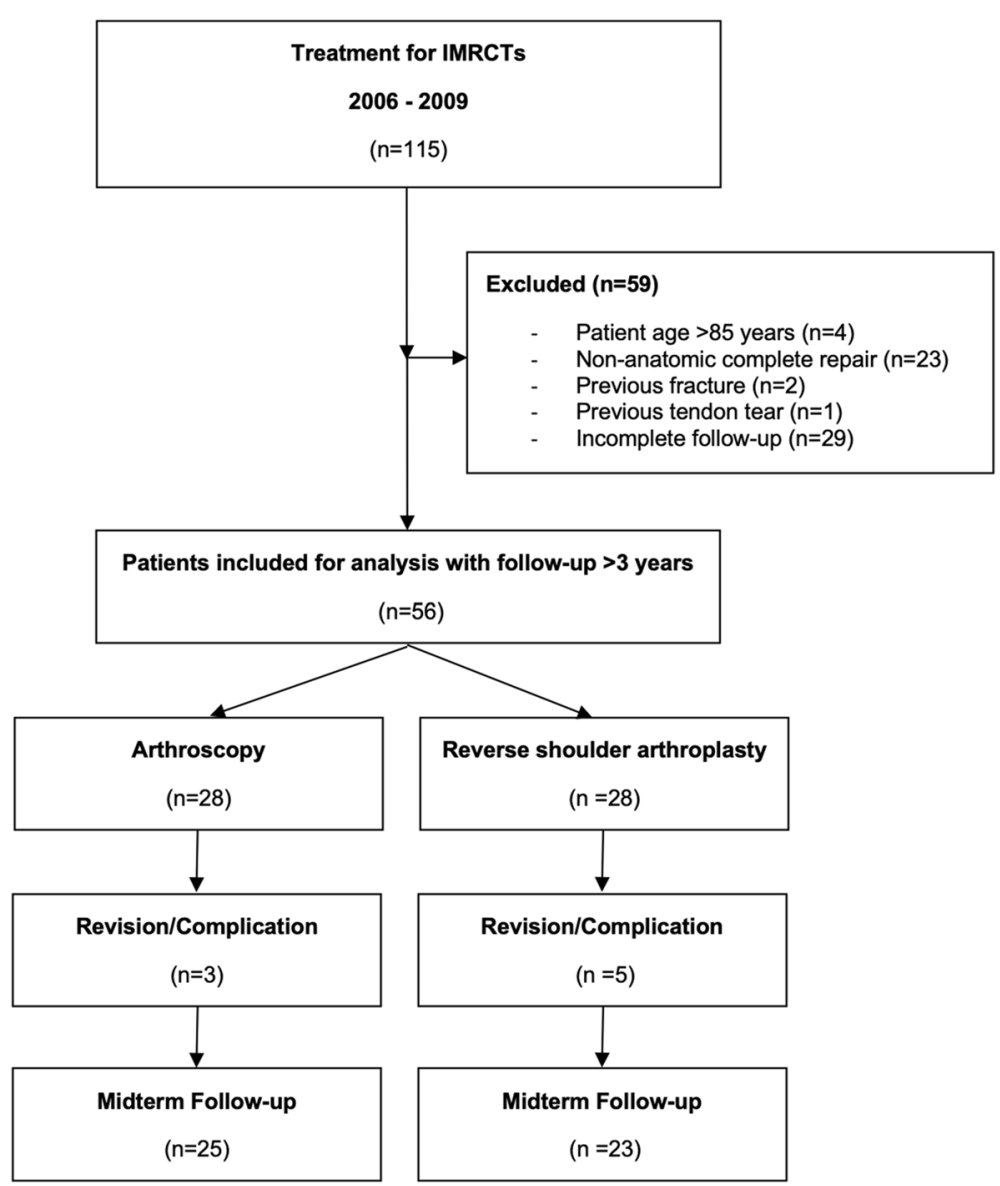

Fig. 1 Flowchart of the enrollment and analysis. IMRCT = irreparable massive rotator cuff tear 
Overall, group A consisted of 28 patients (15 male, 13 female) with a mean age of $70 \pm 7$ (range, from 59 to 81 years) at time of surgery. Of whom, 13 patients $(46 \%)$ were treated by debridement and 15 patients $(54 \%)$ by partial repair of the rotator cuff.

Group B also included 28 patients (10 male, 18 female) with a mean patient age of $72 \pm 7$ years (range, 56 to 85 years) at time of surgery. Severity of cuff arthropathy was comparable between both group A and B $(\mathrm{p}=0.141)$ (Fig. 2). Further baseline data are summarized in Table 1.

\section{Clinical Assessment}

Each patient was pre- and postoperatively evaluated by two independent orthopedic specialists using the same clinical techniques. The Constant Score (CS) as primary outcome measurement together with the Subjective Shoulder Value (SSV, \%), Visual Analog Scores (VAS) and comprehensive physical evaluation including active abduction, forward flexion, external and internal rotation was evaluated at baseline and at latest follow-up. Improvement in outcome measures from pre- to postoperatively were then presented as delta-values $(\Delta)$. In addition, each patient was routinely asked to provide their satisfaction with surgery (very satisfied, satisfied, moderate satisfied, not satisfied) [23, 24]. All surgical complications and required revision surgeries were documented.

\section{Statistical analysis}

Statistical analyses were performed with IBM SPSS Statistics 24.0 software (IBM, Armonk, NY, USA) with the p-values being 2-tailed and the alpha level set to 0.05 . According to a previous study comparing short-term clinical results after arthroscopic debridement and partial repair for IMRCTs [25], a power analysis showed that the minimum sample size was 13 to find significant differences in CS with statistical power of $0.95(\alpha=5 \%)$. Based on an assumed $20 \%$ dropout rate, 16 patients were needed in each group. Furthermore, descriptive statistics (means, standard deviation, minimum and maximum values of continuous variables) were calculated. To analyze statistical differences between group A and $\mathrm{B}$ as well as between pre- and postoperative measures, either the independent $t$ test or the MannWhitney $\mathrm{U}$ test as well as the paired $t$ test or the Wilcoxon matched-pair test (depending on variable distribution) was conducted.

\section{Results}

Overall, all preoperative clinical scores, except for pain, were comparable between group A and group B (Fig. 3). Among group $\mathrm{B}$, previous surgery was not associated with inferior total CS $(p=0.566)$ and SSV $(p=0.692)$. Active range of motion did not differ between both groups with regard to shoulder abduction (group A: $78^{\circ}$ 18 , group B: $68^{\circ} \pm 18 ; p=0.236$ ) and forward flexion (group A: $88^{\circ} \pm 32$, group B: $78^{\circ} \pm 37 ; p=0.145$ ).

During the follow-up period, 3 patients from group A $(11 \%)$ were revised due to a superficial infection $(n=2)$ or anchor loosening $(\mathrm{n}=1)$. In group B, 5 patients $(18 \%)$ sustained a total of 8 complications and underwent a total of 6 revision surgeries. Further information is summarized in Table 2.

Although complication rates were not significantly different $(p=0.705)$, the number of revision surgeries was significantly higher in group B when compared to group

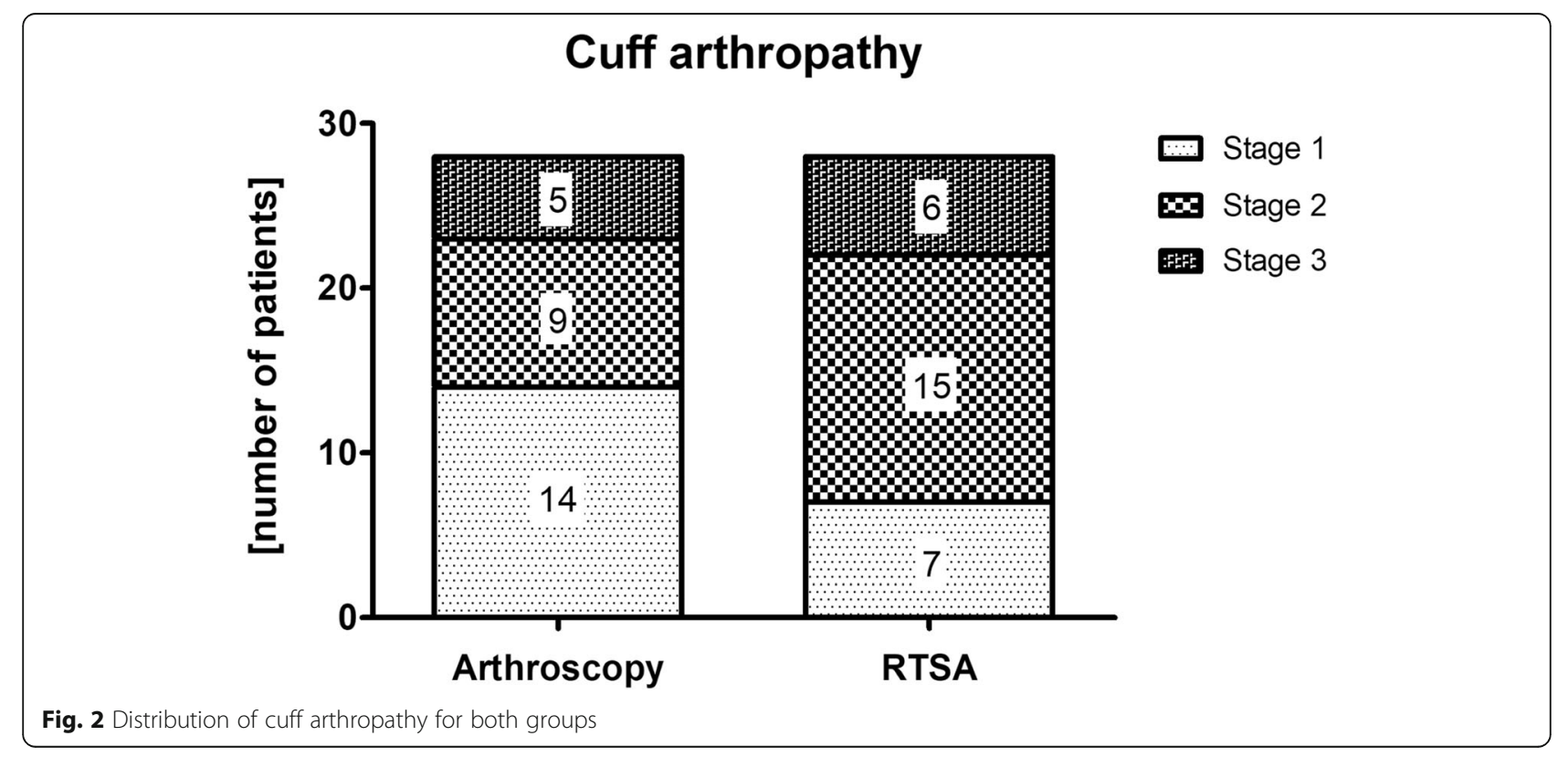


Table 1 Baseline patient characteristics (group A = arthroscopic treatment; group $B=$ reverse total shoulder arthroplasty)

\begin{tabular}{llll}
\hline Variables & $\begin{array}{l}\text { Group A } \\
\mathbf{N = 2 8}\end{array}$ & $\begin{array}{l}\text { Group B } \\
\mathbf{N = 2 8}\end{array}$ & p-value \\
\hline Age at time of surgery, years ${ }^{\mathrm{a}}$ & $70 \pm 7$ & $72 \pm 7$ & 0.228 \\
Gender, male, \% & 36 & 53 & 0.179 \\
Dominant arm, \% & 82 & 77 & 0.670 \\
Previous surgery, \% & 0 & 35 & 0.001 \\
Tendon involvement ${ }^{\mathrm{b}}, \%$ & & & \\
SSP: & 100 & 100 & \\
full-tendon & 100 & 100 & $>0.999$ \\
partial-tendon & 0 & 0 & $>0.999$ \\
ISP: & 100 & 100 & \\
full-tendon & 50 & 71 & 0.450 \\
partial-tendon & 50 & 39 & 0.233 \\
SSC: & 100 & 100 & \\
full-tendon & 21 & 39 & 0.122 \\
Partial-tendon & 79 & 61 & 0.341 \\
Global fatty degeneration index & $1.7 \pm 0.7$ & $1.9 \pm 0.3$ & 0.559 \\
\hline
\end{tabular}

${ }^{\mathrm{a}}$ Data are reported as mean $\pm \mathrm{SD}$, ${ }^{\mathrm{b}}$ full-thickness tendon tear

A $(p=0.041)$. These patients were excluded from further analysis.

The mean follow-up period was $56 \pm 17$ months (range, from 36 to 93 months) with a significant difference between group A $(44 \pm 9$ months) and group B $(68 \pm 14$ months $)(p<0.05)$. The mean duration of surgery was significantly higher $(p<0.05)$ in RTSA when compared to arthroscopic procedures with a mean of $95 \pm 20$ minutes (range, from 63 to 136 minutes) and $54 \pm$ 35 minutes (range, from 12 to 156 minutes), respectively. The majority of patients in both groups were satisfied with their procedure (group A: 84\%; group B: $87 \%$; $=0.755$ ). The total CS was significantly better after arthroscopic treatment $(66 \pm 14)$ when compared to RTSA $(54 \pm 15)$ $(p=0.011)$ (Fig. 4). No significant differences were detected with SSV $(p=0.583)$ and VAS $(\mathrm{p}=0.536)$.

Improvement of total CS from pre- to postoperatively was significant in both group A (mean $\Delta 37 \pm 13$ points; $\mathrm{p}=0.001$ ) and group $\mathrm{B}$ (mean $\Delta 31 \pm 21$ points; $\mathrm{p}=$ 0.001 ). Further information on score improvement is found in Table 3.

With regard to the specific arthroscopic treatment, we did not find any significant differences between debridement $(n=13)$ and partial repair $(n=12)$ at final follow-up. Neither total CS $(64 \pm 18$ points vs. $68 \pm 9$ points; $p=$ $0.586)$ nor SSV (76 \% \pm 11 versus $76 \% \pm 16 ; p=0.0955)$ as well as VAS ( $2 \pm 2$ points vs. $1 \pm 2$ points; $p=0.758)$ were influenced by final treatment. Furthermore, score improvement was comparable (CS: $39 \pm 12$ points vs. $35 \pm 15$ points, $p=0.468$; SSV: $42 \% \pm 13$ vs. $43 \% \pm 24, p=0.853$; VAS: $5 \pm 2$ points vs. $5 \pm 3$ points, $p=0.877$ ).

\section{Discussion}

The most important finding of this study is that in nonarthritic shoulders both joint-preserving and jointreplacing procedures yielded good clinical midterm outcomes for the treatment of degenerative IMRCTs.

\section{Constant Score \\ Preoperative}

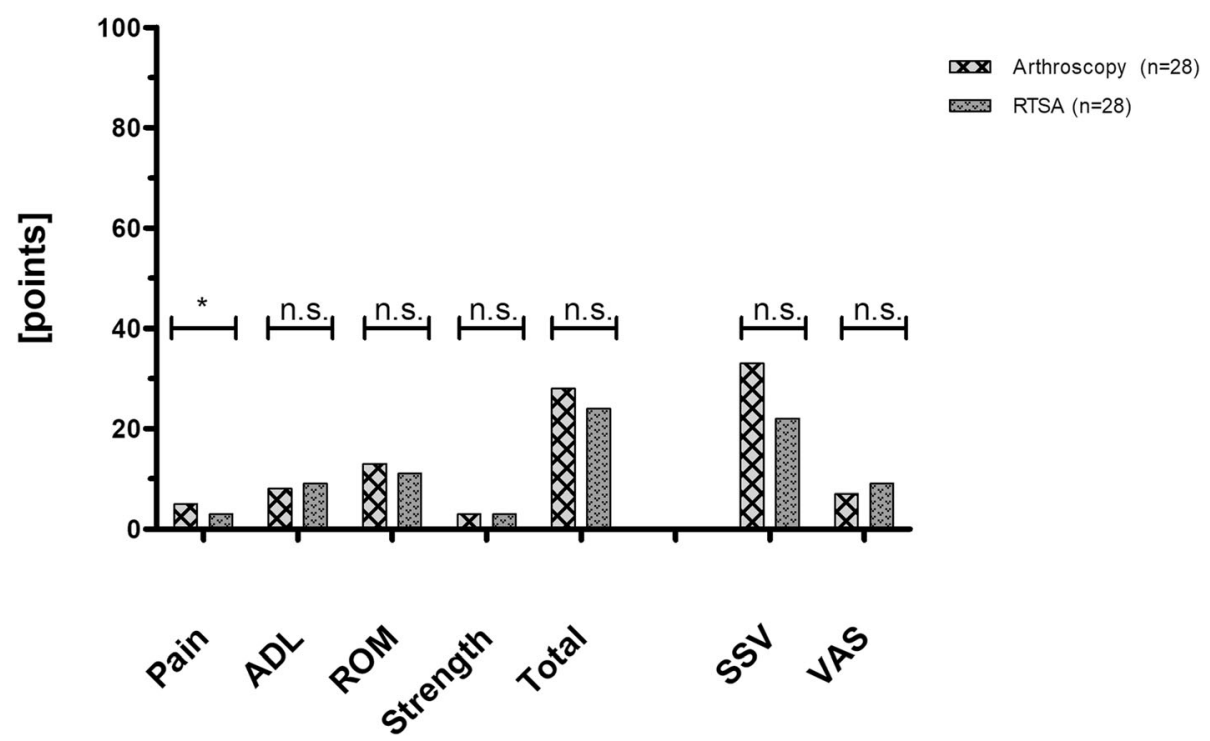

Fig. 3 Preoperative outcome measures for group A (arthroscopic treatment) and group B (reverse total shoulder arthroplasty (RTSA)). Significance level indicated $(*) . A D L=$ activity of daily life; $R O M=$ range of motion; SSV = subjective shoulder value; VAS = visual analogue scale 
Table 2 Required revision surgeries on the affected shoulder during follow-up period

\begin{tabular}{|c|c|c|c|c|c|c|c|c|c|c|c|}
\hline & Technique & $\mathrm{Age}^{\mathrm{a}}$ & Gender & $\begin{array}{l}\text { Previous } \\
\text { surgery }\end{array}$ & $\begin{array}{l}\text { Time } \\
\text { period }^{\mathbf{b}}\end{array}$ & Reason & Revision surgery & $\begin{array}{l}f / \\
u^{c}\end{array}$ & Satisfaction $^{d}$ & $\begin{array}{l}\Delta \\
\text { SSV }\end{array}$ & $\begin{array}{l}\Delta \\
\text { CS }\end{array}$ \\
\hline \multirow[t]{3}{*}{$\begin{array}{l}\text { Group } \\
\text { A }\end{array}$} & PR & 68 & Male & No & 9 days & Superficial infection & $\begin{array}{l}\text { Arthroscopic joint } \\
\text { lavage }\end{array}$ & 4 & Satisfied & 60 & 46 \\
\hline & $P R$ & 73 & Male & No & 9 days & Superficial infection & Open joint lavage & 5 & Satisfied & 30 & 30 \\
\hline & $P R$ & 68 & Female & No & 40 days & Anchor loosening & $\begin{array}{l}\text { Arthroscopic anchor } \\
\text { removal }\end{array}$ & 3 & Satisfied & 80 & 52 \\
\hline \multirow{8}{*}{$\begin{array}{l}\text { Group } \\
\text { B }\end{array}$} & RTSA & 85 & Male & No & 78 days & Early dislocation & Closed reduction & & & & \\
\hline & & & & & 140 days & Second dislocation & Humeral revision & 1 & n.a. & n.a. & 30 \\
\hline & RTSA & 73 & Male & No & 28 days & Early dislocation & Closed reduction & & & & \\
\hline & & & & & 6 years & Static subluxation & Glenoid revision & 6 & Satisfied & 20 & 18 \\
\hline & RTSA & 77 & Female & Yes & 2.5 years & $\begin{array}{l}\text { Acromion stress } \\
\text { fracture }\end{array}$ & Osteosynthesis & 3 & n.a & n.a & 14 \\
\hline & RTSA & 79 & Female & No & 1 year & $\begin{array}{l}\text { Aseptic glenoid } \\
\text { loosening }\end{array}$ & Glenoid revision & & & & \\
\hline & & & & & 5 years & $\begin{array}{l}\text { Aseptic glenoid } \\
\text { loosening }\end{array}$ & Conversion to HA & 6 & n.a. & n.a. & 9 \\
\hline & RTSA & 69 & Female & No & 3 years & $\begin{array}{l}\text { Traumatic axillary } \\
\text { nerve palsy }\end{array}$ & Open patch plastic & 4 & n.a. & n.a. & 48 \\
\hline
\end{tabular}

${ }^{a}$ patient age at time of initial surgery; ${ }^{b}$ time period between initial surgery and revision surgery; ${ }^{c}$ time period between initial surgery and latest follow-up (f/u); ${ }^{d}$ satisfaction with initial treatment; SSV Subjective Shoulder Value; CS Constant Score; $\Delta$ - value = difference between pre- and postoperative score; $P R$ partial repair; RTSA reverse total shoulder arthroplasty; n.a. not available

A variety of factors need to be considered for treatment of massive RCTs. Despite of modern preoperative imaging techniques, repairability of massive RCTs cannot always be predicted. Indeed, it was previously shown that a complete repair is most favorable in terms of functional and satisfactory improvement, with rates as low as $2.4 \%$ needing a secondary conversion to RTSA in a long-term follow-up [26]. However, Goutallier et al. stated that a fatty muscle infiltration of more than $50 \%$ resulted in inferior functional outcome following

\section{Constant Score} Postoperative
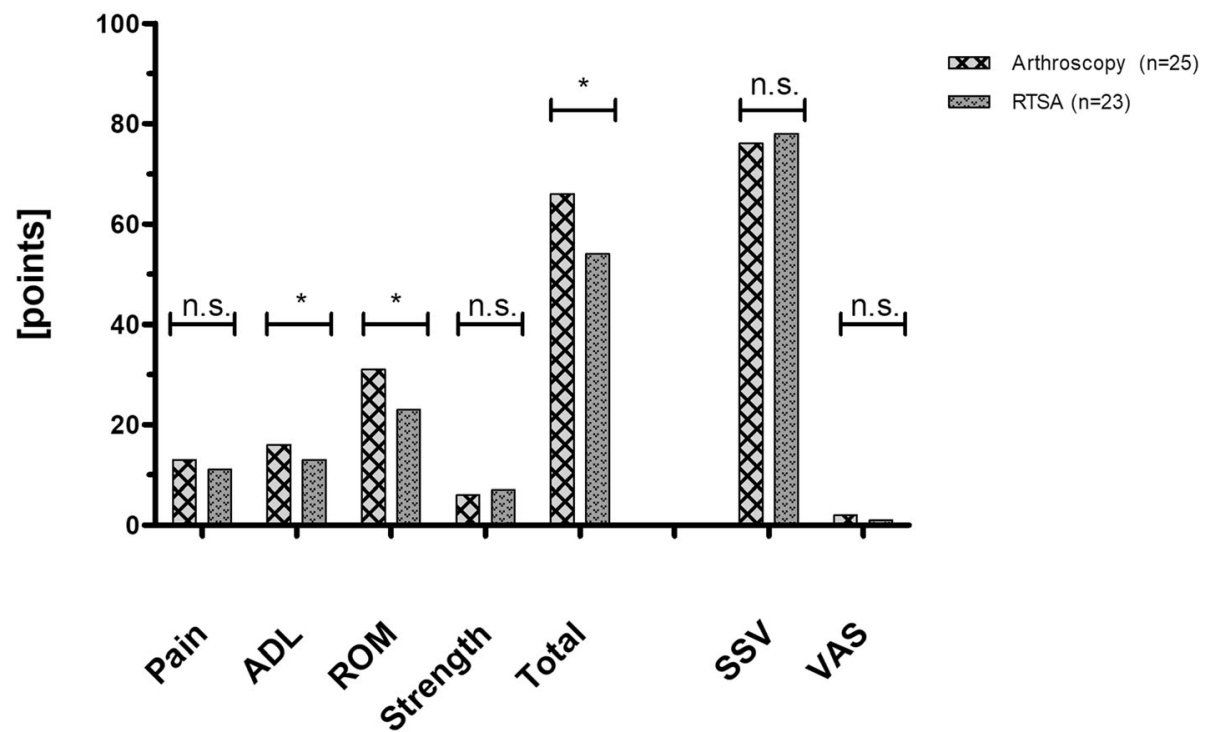

Fig. 4 Postoperative outcome measures. Significance level indicated $\left(^{*}\right)$. RTSA = reverse total shoulder arthroplasty; ADL = activity of daily life; $\mathrm{ROM}=$ range of motion; SSV = subjective shoulder value; $\mathrm{VAS}=$ visual analogue scale 
Table 3 Functional improvement from pre- to postoperatively ( $\triangle$-value)

\begin{tabular}{|c|c|c|c|}
\hline Variables $^{\mathrm{a}}$ & $\begin{array}{l}\text { Group A } \\
N=25\end{array}$ & $\begin{array}{l}\text { Group B } \\
N=23\end{array}$ & $p$-value \\
\hline \multicolumn{4}{|c|}{ Constant Score, points } \\
\hline$\Delta$-value & $37 \pm 13$ & $31 \pm 21$ & 0.224 \\
\hline \multicolumn{4}{|c|}{ Subjective Shoulder Value, \% } \\
\hline$\Delta$-value & $43 \pm 18$ & $62 \pm 15$ & 0.001 \\
\hline \multicolumn{4}{|c|}{ Visual Analog Scale, points } \\
\hline$\Delta$-value & $5 \pm 3$ & $7 \pm 2$ & 0.089 \\
\hline
\end{tabular}

${ }^{\mathrm{a}}$ Data are reported as mean $\pm \mathrm{SD}$

complete rotator cuff repair [5]. On the contrary, Burkhart et al. found that even patients with muscle degeneration above $50 \%$ would significantly benefit from an arthroscopic reattachment or partial repair [13]. These findings were supported by Cuff et al. investigating arthroscopic partial repair for IMRCTs [27]. Although patients without osteoarthritis were evaluated in their study, in contrast to our population, pseudoparetic patients were excluded. Our data supports that even these patients would benefit from a partial repair or even simple debridement. Considering found satisfaction, pain relief, and functional gain, primary arthroscopic treatment could be considered in the management of selected patients with IMRCTs unaccompanied by glenohumeral osteoarthritic changes. Imperatively, treatment options should be discussed thoroughly with the patient. Even conservative treatment was shown to yield satisfactory results in patients with lower demands and successful compensation upon midterm follow-up, however, progression of glenohumeral osteoarthritis as well as possible conversion from repairable to irreparable cuff tears were observed [4]. After 10 years, Zumstein et al. reported osteoarthritic changes in $61 \%$ of patients with a significant progression between mid- and long-term assessment following open rotator cuff repair for massive RCTs [28]. A recent long-term follow-up after open rotator cuff repair by Herve et al. reported secondary glenohumeral osteoarthritis in $29 \%$ of all patients with even higher rates in patients with massive RCTs [29]. Both of these studies excluded irreparable lesions in their evaluation. Although secondary glenohumeral osteoarthritis following incomplete rotator cuff repair was not evaluated in our study, this progressive condition might be an important mid- to long-term issue with possibly even higher rates than reported with full repair. In the context of the patient's age, the decision to undertake first-line arthroscopic treatment should consider these secondary consequences. Denard et al. investigated the effectiveness of arthroscopic complete and partial repair for massive RCTs with active forward flexion and elevation under $90^{\circ}$ and found a success rate for reversing the pseudoparetic state in $94.6 \%$ of all patients [30]. In addition to their findings our study shows that the results after arthroscopic treatment are comparable in functional outcome to those following RTSA.

Sirveaux at al. propose RTSA to be reserved for elderly patients in consideration of concomitant complications, such as material loosening, notching and infection, as well as limited revision options [31]. Zumstein et al. reported an overall complication rate after RTSA of $24 \%$, with instability and infection being most noticeable [32]. Our study underlines those high complication rates, with instability being the major reason for revision surgery (Table 3). Long-term results of RTSA in more active patients before the age of 60 years showed persistent improvement in range of motion and pain relief, but also reported substantial complication rates [33]. Recent cost-effectiveness analyses found primary arthroscopic procedures even upon potential failure with secondary conversion to RTSA to be the economically superior strategy $[34,35]$. Boileau et al. examined patients treated with RTSA after failed rotator cuff repair. They found overall significant improvement in range of motion and pain relief, although results seem to be inferior to primary RTSA [36]. Underlining these findings, a recent study by Carducci et al. investigated influences on inferior functional outcomes following RTSA without further complications and found a significant correlation to prior failed surgical interventions [37]. In our study population we did not observe any differences in shoulder function within the RTSA group. However, the smaller patient number could lead to biased results.

Our study indicates that despite of comparable functional and satisfactory improvement, increased complication rates and surgical invasiveness outweigh the benefits of primary RTSA and therefore reserve this procedure to a second-line treatment in pseudoparetic patients without any signs of severe cuff arthropathy. Nevertheless, certain limitations have to be considered. First, all inherent disadvantages of retrospective evaluations apply to the present study. Due to the small sample size, the study might be underpowered to detect small effect sizes also within the groups. In order to counteract the limited cohort sizes and underline homogeneity for better comparability, we strictly defined inclusion and exclusion criteria for comparison and conducted a power analysis prior to the investigation. Although an individualized treatment was sought for each patient, it cannot be ruled out that a certain selection bias can occur, primarily due to the patient's activity levels. Another potential bias is the difference in follow-up time. Mean follow-up for group A was shorter, which could underestimate a decline in function and therefore patient's satisfaction over time. All procedures were performed by three different surgeons, which could possibly 
bias the outcome. Given the level of experience and years of training in the same institution this is highly unlikely.

As treatment in patients with severe shoulder complaints secondary to IMRCTs is still a great challenge and literature lacks in comparison studies at the highest level, it is not possible to give an algorithmic approach. Nevertheless, we were able to show that arthroscopic treatment of patients with massive RCTs showed comparable results to those of RTSA, even if complete repair was not achieved. Thus, our study is of great value to further simplify decision-making. Given the good clinical results, arthroscopic treatment is highly efficient in the treatment of IMRCTs without osteoarthritis, even in pseudoparetic shoulder. However, possible implications, such as secondary glenohumeral osteoarthritis, potentially inferior functional outcome following secondary joint replacement, and economic factors need to be clarified in further research.

\section{Conclusions}

Both, arthroscopic procedures and RTSA in the treatment of IMRCTs achieved considerable midterm improvement in pain relief and gain of function in pseudoparetic shoulders without glenohumeral osteoarthritis.

\section{Abbreviations}

RCT: Rotator cuff tear; IMRCT: Irreparable massive rotator cuff tears; RTSA: Reverse total shoulder arthroplasty; SSP: Supraspinatus; ISP: Infraspinatus; SSC: Subscapularis; AHI: Acromiohumeral interval; LBS: Long head of the biceps; GFDI: Global fatty degeneration index; CS: Constant Score; SSV: Subjective Shoulder Value; VAS: Visual analogue scale

\section{Acknowledgements}

The authors want to thank Bernhard Kriegleder (BK) and Sylvia Salem (SS) for their assistance and participation in this study.

\section{Authors' contributions}

All listed authors have contributed substantially to this work, read and approved the final manuscript: FP, WA, PH for the study conception and design; FP, LP, BL, PH for the data collection; FP, PS, LP, BL, PM for the data analysis; FP, WA, PM, PH for the data interpretation; FP, PS, PH for the drafting of the manuscript, the figures, and the literature research.

\section{Funding}

Not applicable.

\section{Availability of data and materials}

The datasets used and analysed during the current study are available from the corresponding author on reasonable request.

\section{Ethics approval and consent to participate}

This study was approved by the local ethical committee (Krankenhaus der Barmherzigen Schwestern Wien: 201212_EK0103).

\section{Consent for publication}

Not applicable.

\section{Competing interests}

The authors declare that they have no competing interests.

\section{Author details}

${ }^{1}$ Center for Musculoskeletal Surgery, Charité - Universitaetsmedizin, Berlin, Germany. ${ }^{2}$ Department of Orthopedics and Traumatology, Paracelsus Medical University, Salzburg, Austria. ${ }^{3}$ Department of Orthopedics, St. Vincent Hospital Vienna, Hartmanngasse 15/9, 1050 Vienna, Austria. ${ }^{4}$ Austrian Research Group for Regenerative and Orthopedic Medicine, Hartmanngasse 15/9, 1050 Vienna, Austria.

Received: 29 October 2020 Accepted: 4 February 2021

Published online: 16 February 2021

\section{References}

1. Gerber C, Fuchs B, Hodler J. The results of repair of massive tears of the rotator cuff. The Journal of bone joint surgery American volume. 2000;82(4): 505-15.

2. Meyer DC, Lajtai G, von Rechenberg B, Pfirrmann CWA, Gerber C: Tendon retracts more than muscle in experimental chronic tears of the rotator cuff. J Bone Joint Surg Br 2006, 88b(11):1533-1538.

3. Gerber C, Wirth SH, Farshad M. Treatment options for massive rotator cuff tears. J Shoulder Elb Surg. 2011;20(2):20-9.

4. Zingg PO, Jost B, Sukthankar A, Buhler M, Pfirrmann CW, Gerber C. Clinical and structural outcomes of nonoperative management of massive rotator cuff tears. J Bone Joint Surg Am. 2007;89(9):1928-34.

5. Goutallier D, Postel JM, Bernageau J, Lavau L, Voisin MC. Fatty muscle degeneration in cuff ruptures. Pre- and postoperative evaluation by CT scan. Clin Orthop Relat Res 1994(304):78-83.

6. Saupe N, Pfirrmann CW, Schmid MR, Jost B, Werner CM, Zanetti M. Association between rotator cuff abnormalities and reduced acromiohumeral distance. AJR Am J Roentgenol. 2006;187(2):376-82.

7. Adamson GJ, Tibone JE. Ten-year assessment of primary rotator cuff repairs. J Shoulder Elbow Surg. 1993;2(2):57-63.

8. Cofield RH. Rotator cuff disease of the shoulder. The Journal of bone joint surgery American volume. 1985;67(6):974-9.

9. Tokish JM, Alexander TC, Kissenberth MJ, Hawkins RJ. Pseudoparalysis: a systematic review of term definitions, treatment approaches, and outcomes of management techniques. J Shoulder Elbow Surg. 2017;26(6):e177-87.

10. Werner CM, Steinmann PA, Gilbart M, Gerber C. Treatment of painful pseudoparesis due to irreparable rotator cuff dysfunction with the Delta III reverse-ball-and-socket total shoulder prosthesis. J Bone Joint Surg Am. 2005;87(7):1476-86.

11. Heuberer PR, Kolblinger R, Buchleitner S, Pauzenberger L, Laky B, Auffarth A, Moroder P, Salem S, Kriegleder B, Anderl W. Arthroscopic management of massive rotator cuff tears: an evaluation of debridement, complete, and partial repair with and without force couple restoration. Knee Surg Sports Traumatol Arthrosc. 2016;24(12):3828-37.

12. Kim JR, Cho YS, Ryu KJ, Kim JH. Clinical and radiographic outcomes after arthroscopic repair of massive rotator cuff tears using a suture bridge technique: assessment of repair integrity on magnetic resonance imaging. Am J Sports Med. 2012;40(4):786-93.

13. Burkhart SS, Barth JR, Richards DP, Zlatkin MB, Larsen M. Arthroscopic repair of massive rotator cuff tears with stage 3 and 4 fatty degeneration. Arthroscopy. 2007;23(4):347-54.

14. Richards DP, Burkhart SS. Arthroscopic debridement and capsular release for glenohumeral osteoarthritis. Arthroscopy: the journal of arthroscopic related surgery : official publication of the Arthroscopy Association of North America the International Arthroscopy Association. 2007;23(9):1019-22.

15. Gerber C, Maquieira G, Espinosa N. Latissimus dorsi transfer for the treatment of irreparable rotator cuff tears. The Journal of bone joint surgery American volume. 2006;88(1):113-20.

16. Rockwood CA Jr, Williams GR Jr, Burkhead WZ. Jr.: Debridement of degenerative, irreparable lesions of the rotator cuff. J Bone Joint Surg Am. 1995;77(6):857-66.

17. Burkhart SS, Nottage WM, Ogilvie-Harris DJ, Kohn HS, Pachelli A. Partial repair of irreparable rotator cuff tears. Arthroscopy. 1994;10(4):363-70.

18. Mulieri P, Dunning P, Klein S, Pupello D, Frankle M. Reverse shoulder arthroplasty for the treatment of irreparable rotator cuff tear without glenohumeral arthritis. J Bone Joint Surg Am. 2010;92(15):2544-56.

19. Sevivas N, Ferreira N, Andrade R, Moreira P, Portugal R, Alves D, Vieira da Silva M, Sousa N, Salgado AJ, Espregueira-Mendes J. Reverse shoulder arthroplasty for irreparable massive rotator cuff tears: a systematic review 
with meta-analysis and meta-regression. J Shoulder Elbow Surg. 2017;26(9): e265-77.

20. Fuchs B, Weishaupt D, Zanetti M, Hodler J, Gerber C. Fatty degeneration of the muscles of the rotator cuff: assessment by computed tomography versus magnetic resonance imaging. J Shoulder Elbow Surg. 1999;8(6):599-605.

21. Hamada K, Fukuda H, Mikasa M, Kobayashi Y. Roentgenographic findings in massive rotator cuff tears. A long-term observation. Clinical orthopaedics and related research 1990(254):92-96.

22. Goutallier D, Postel JM, Gleyze P, Leguilloux P, Van Driessche S. Influence of cuff muscle fatty degeneration on anatomic and functional outcomes after simple suture of full-thickness tears. J Shoulder Elbow Surg. 2003;12(6):550-4

23. Constant CR, Murley AH. A clinical method of functional assessment of the shoulder. Clin Orthop Relat Res. 1987;214:160-4.

24. Gilbart MK, Gerber C. Comparison of the subjective shoulder value and the Constant score. J Shoulder Elbow Surg. 2007:16(6):717-21.

25. Berth A, Neumann W, Awiszus F, Pap G. Massive rotator cuff tears: functional outcome after debridement or arthroscopic partial repair. J Orthop Traumatol. 2010;11(1):13-20.

26. Collin P, Betz M, Herve A, Walch G, Mansat P, Favard L, Colmar M, Francois Kempf J, Thomazeau H, Gerber C. Clinical and structural outcome 20 years after repair of massive rotator cuff tears. J Shoulder Elbow Surg. 2020;29(3): 521-6.

27. Cuff DJ, Pupello DR, Santoni BG. Partial rotator cuff repair and biceps tenotomy for the treatment of patients with massive cuff tears and retained overhead elevation: midterm outcomes with a minimum 5 years of followup. J Shoulder Elbow Surg. 2016;25(11):1803-9.

28. Zumstein MA, Jost B, Hempel J, Hodler J, Gerber C. The clinical and structural long-term results of open repair of massive tears of the rotator cuff. J Bone Joint Surg Am. 2008;90(11):2423-31.

29. Herve A, Thomazeau H, Favard L, Colmar M, Mansat P, Walch G, Betz M Kempf JF, Collin P. Clinical and radiological outcomes of osteoarthritis twenty years after rotator cuff repair. Orthop Traumatol Surg Res. 2019; 105(5):813-8.

30. Denard PJ, Ladermann A, Brady PC, Narbona P, Adams CR, Arrigoni P, Huberty D, Zlatkin MB, Sanders TG, Burkhart SS. Pseudoparalysis From a Massive Rotator Cuff Tear Is Reliably Reversed With an Arthroscopic Rotator Cuff Repair in Patients Without Preoperative Glenohumeral Arthritis. Am J Sports Med. 2015;43(10):2373-8.

31. Sirveaux F, Favard L, Oudet D, Huquet D, Walch G, Mole D. Grammont inverted total shoulder arthroplasty in the treatment of glenohumeral osteoarthritis with massive rupture of the cuff. Results of a multicentre study of 80 shoulders. J Bone Joint Surg Br. 2004;86(3):388-95.

32. Zumstein MA, Pinedo M, Old J, Boileau P. Problems, complications, reoperations, and revisions in reverse total shoulder arthroplasty: a systematic review. J Shoulder Elbow Surg. 2011;20(1):146-57.

33. Ernstbrunner L, Suter A, Catanzaro S, Rahm S, Gerber C. Reverse Total Shoulder Arthroplasty for Massive, Irreparable Rotator Cuff Tears Before the Age of 60 Years: Long-Term Results. The Journal of bone joint surgery American volume. 2017;99(20):1721-9.

34. Dornan GJ, Katthagen JC, Tahal DS, Petri M, Greenspoon JA, Denard PJ, Burkhart SS, Millett PJ. Cost-Effectiveness of Arthroscopic Rotator Cuff Repair Versus Reverse Total Shoulder Arthroplasty for the Treatment of Massive Rotator Cuff Tears in Patients With Pseudoparalysis and Nonarthritic Shoulders. Arthroscopy. 2017;33(4):716-25.

35. Makhni EC, Swart E, Steinhaus ME, Mather RC 3rd, Levine WN, Bach BR Jr, Romeo AA, Verma NN. Cost-Effectiveness of Reverse Total Shoulder Arthroplasty Versus Arthroscopic Rotator Cuff Repair for Symptomatic Large and Massive Rotator Cuff Tears. Arthroscopy. 2016;32(9):1771-80.

36. Boileau P, Gonzalez JF, Chuinard C, Bicknell R, Walch G. Reverse total shoulder arthroplasty after failed rotator cuff surgery. J Shoulder Elbow Surg. 2009:18(4):600-6.

37. Carducci MP, Zimmer ZR, Jawa A. Predictors of unsatisfactory patient outcomes in primary reverse total shoulder arthroplasty. J Shoulder Elbow Surg 2019.

\section{Publisher's Note}

Springer Nature remains neutral with regard to jurisdictional claims in published maps and institutional affiliations.

\section{Ready to submit your research? Choose BMC and benefit from:}

- fast, convenient online submission

- thorough peer review by experienced researchers in your field

- rapid publication on acceptance

- support for research data, including large and complex data types

- gold Open Access which fosters wider collaboration and increased citations

- maximum visibility for your research: over $100 \mathrm{M}$ website views per year

At BMC, research is always in progress.

Learn more biomedcentral.com/submissions 